\title{
Hybrid Processing of Ti-6Al-4V Using Plasma Immersion Ion Implantation Combined with Plasma Nitriding
}

\author{
Maria Margareth da Silva*, Mário Ueda ${ }^{\mathrm{b}}$, Choyu Otanic, Helfried Reuther, \\ Carlos Maurício Lepienski, Paulo César Soares Junior, Jorge Otubo \\ ${ }^{a}$ Divisão de Engenharia Mecânica-Aeronáutica, Instituto Tecnológico de Aeronáutica, \\ Praça Mal. Eduardo Gomes, 50, 12228-900 S. J. Campos - SP, Brazil \\ ${ }^{\mathrm{b}}$ Laboratório Associado de Plasma, Instituto Nacional de Pesquisas, S. J. Campos - SP, Brazil \\ ${ }^{`}$ Departamento de Física, Instituto Tecnológico de Aeronáutica, S. J. Campos - SP, Brazil \\ ${ }^{\mathrm{d} I n s t i t u t e}$ of Ion Beam Physics and Materials Research, Center Rossendorf, Dresden, Germany

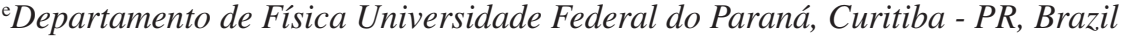

Received: December 2, 2004; Revised: December 6, 2005

\begin{abstract}
Based on the fact that the Ti-6Al-4V alloy has good mechanical properties, excellent resistance to corrosion and also excellent biocompatibility, however with low wear resistance, this work aims to test plasma processes or combination of plasma and ion implantation processes to improve these characteristics. Two types of processing were used: two steps PIII (Plasma Immersion Ion Implantation) combined with PN (Plasma Nitriding) and single step PIII treatment. According to Auger Electron Spectroscopy (AES) results, the best solution was obtained by PIII for 150 minutes resulting in $\sim 65 \mathrm{~nm}$ of nitrogen implanted layer, while the sample treated with PIII (75 minutes) and PN (75 minutes) reached $\sim 35 \mathrm{~nm}$ implanted layer. The improvement of surface properties could also be confirmed by the nanoindentation technique, with values of hardness increasing for both processes. AFM (Atomic Force Microscopy) characterization showed that the single step PIII process presented greater efficiency than the duplex process $(\mathrm{PIII}+\mathrm{PN})$, probably due to the sputtering occurring during the second step (PN) removing partially the implanted layer of first step (PIII).
\end{abstract}

Keywords: Ti6Al4V, Plasma Nitriding, Plasma Immersion Ion Implantation, mechanical properties

\section{Introduction}

The Ti-6Al-4V alloy, is one of the most used titanium alloys in aeronautical industries and in biomedical applications, due to its excellent combination of mechanical resistance, toughness and excellent corrosion resistance ${ }^{1,2}$ being considered chemically stable $^{3}$. The excellent corrosion resistance and biocompatibility can be attributed to the formation of a passive titanium oxide film on titanium and its alloys avoiding further oxidation of the bulk $\mathrm{k}^{4-11}$. The Ti-6Al-4V alloy is classified as $\alpha+\beta$ alloy presenting specific weight of $4.43 \mathrm{~g} / \mathrm{cm}^{3}$, therefore $56 \%$ of the corresponding value to the steel and approximately double to the aluminum density ${ }^{12,13}$. However, the alloy presents inadequate tribological properties, with high friction coefficient of around $0.8{ }^{14}$. In wear absence, the titanium and its alloys possesses excellent corrosion resistance in many enviroments including saline solutions, similar to corporeal fluids. However in the presence of localized wear, intense corrosion could occur ${ }^{15,13}$. To improve corrosion and wear resistance, as well as fatigue strength, surface treatments such as cold plasma plating and ionic implantation have been investigated ${ }^{16,13}$.

The present work aims to improve the surface mechanical properties of the Ti-6Al-4V alloy by the combination of two plasma assisted processes: Plasma Nitriding and Plasma Immersion Ion Implantation or the combination of both processes to obtain thicker nitrogen implanted layer.

\section{Experimental Procedure}

The experiments were carried out at Laboratórios Associados de Plasma - LAP of Instituto Nacional de Pesquisas Espaciais
- INPE. The samples with $10 \mathrm{~mm}$ in diameter by $1 \mathrm{~mm}$ in thickness were polished to mirror like surface, mounted in a sample holder and then introduced to the reactor chamber (Figure 1). The plasma chamber was initially evacuated down to $\sim 2.1 \times 10^{-3} \mathrm{~Pa}$, and then filled with argon gas for approximately 10 minutes. After this purging stage, the argon gas was replaced by nitrogen. The experimental conditions are presented in Table 1 . The ion bombardment heats the sample up to around $400{ }^{\circ} \mathrm{C}$. The surface hardness was analyzed by nanoindentation technique, the composition profile by Auger Electron Spectroscopy (AES) and the surface topography by Atomic Force Microscopy (AFM).

\section{Results and Discussions}

The Figure 2 presents the hardness profile obtained by nanoindentation technique for the specimens prepared according to Table 1. The hardness varied from 3.8 to $4.7 \mathrm{GPa}$ and 4.3 to $6.1 \mathrm{GPa}$ respectively for untreated (reference) sample and sample \#4 treated for process PIII during 150 minutes resulting in an hardness increase of approximately $29.8 \%$ in the maximum hardness values. For the two step process sample PIII (75 minutes) + PN (240 minutes) the hardness values varied from 4.0 to $6.6 \mathrm{GPa}$, that is, around $40.4 \%$ increase. The highest hardness values was presented by the sample \#1 treated according to PIII (75 minutes) + PN (75 minutes), with an increase of about $59.6 \%$, with values ranging from 4.2 to $7.5 \mathrm{GPa}$.

The Figure 3 a presents the composition profile obtained by AES of untreated Ti-6Al-4V alloy used as a reference showing thin layer of carbon and oxygen, probably, $\mathrm{TiC}$ and $\mathrm{TiO}_{2}$. The Figure $3 \mathrm{~b}$ shows 




Figure 1. Schematic diagram for plasma immersion ion implantation apparatus.

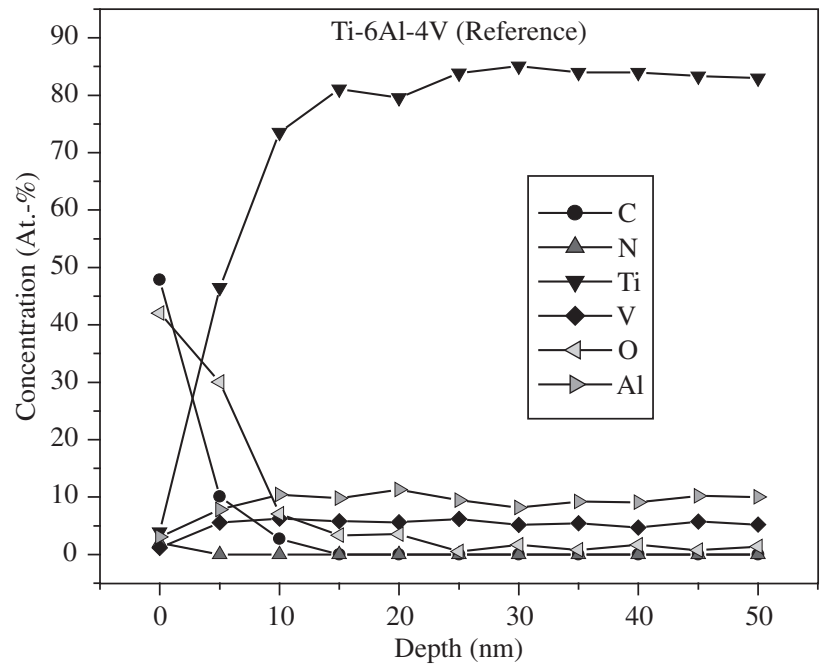

(a)

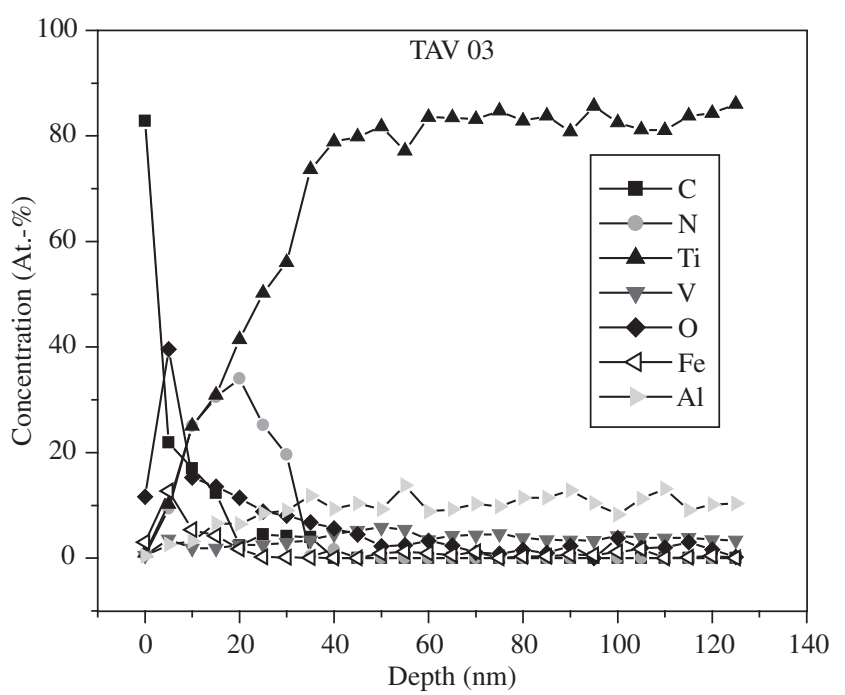

(b)

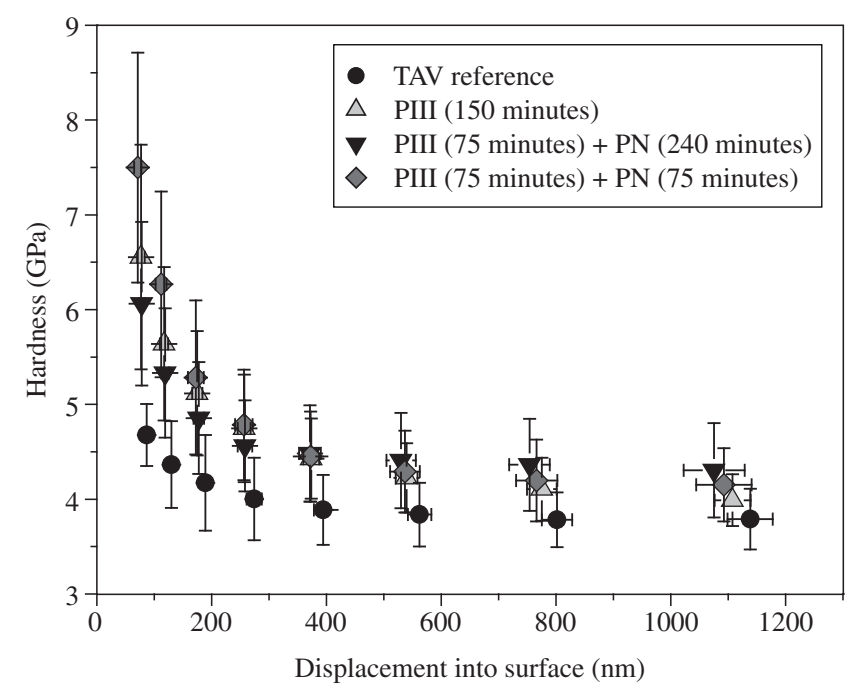

Figure 2. Superficial hardness (nanoindentation) of the samples treated according to Table 1 including reference sample.

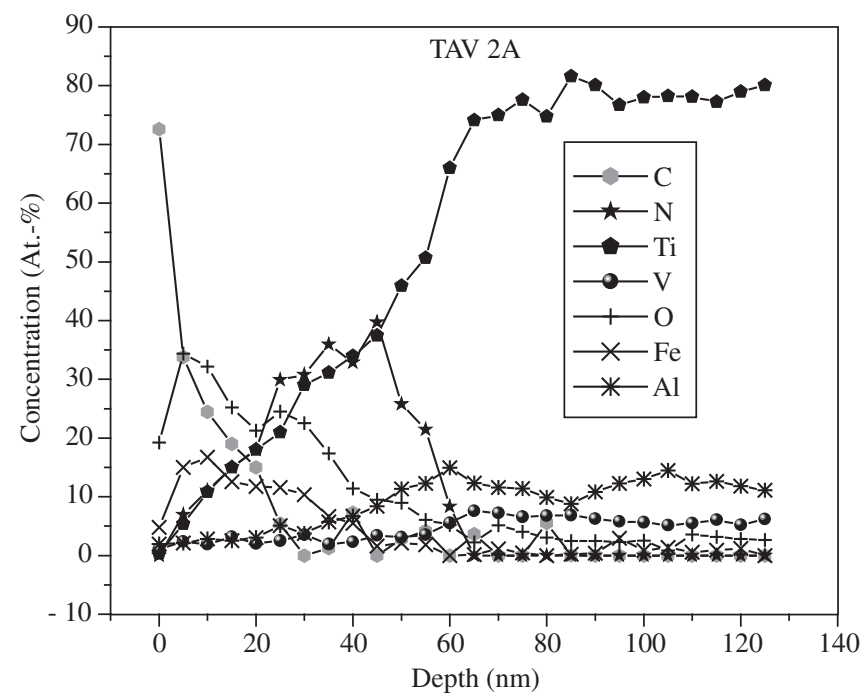

(c)



(d)

Figura 3. a) AES - untreated sample; b) AES - sample \#3 - PIII (75 minutes) + PN (75 minutes); c) AES - sample \#2 - PIII (150 minutes); and d) AES - sample \#6 - PIII (75 minutes) + PN (240 minutes). 
Table 1. Experimental parameters adopted in the tests.

\begin{tabular}{ll}
\hline Sample \# & \multicolumn{1}{c}{ Treatment } \\
\hline 1 and 3 & PIII \\
& Frequency: $400 \mathrm{~Hz}$, \\
& pulse: $20 \mu \mathrm{s}$ \\
& voltage: $15 \mathrm{kV}$ \\
& working pressure: $8 \times 10^{-2} \mathrm{~Pa}$ \\
& time: 75 minutes \\
& PN \\
& working pressure: $8 \times 10^{-2} \mathrm{~Pa}$ voltage: $-700 \mathrm{~V}$ \\
& Time: 75 minutes \\
& PIII \\
& frequency: $400 \mathrm{~Hz}$, \\
& pulso: $20 \mu \mathrm{s}$, \\
& voltage: $17 \mathrm{kV}$, \\
& work pressure: $7.2 \times 10^{-2} \mathrm{~Pa}$ \\
& time: 150 minutes \\
& PIII \\
& frequency: $400 \mathrm{~Hz}$, \\
& pulso: $20 \mu \mathrm{s}$ \\
& voltage: $17 \mathrm{kV}$ \\
& working pressure: $8 \times 10^{-2} \mathrm{~Pa}$ time: 75 minutes \\
& PN 6 and 6 \\
& working pressure: $8 \times 10^{-2} \mathrm{~Pa}$ voltage: $-750 \mathrm{~V}$ \\
& time: 240 minutes. \\
& \\
&
\end{tabular}

the composition profile of the sample \#3 with nitrogen layer thickness of approximately $35 \mathrm{~nm}$, with maximum atomic concentration of nitrogen of about $35 \%$. The sample \#2, Figure 3c, presented the highest nitrogen layer thickness of $65 \mathrm{~nm}$, for maximum atomic concentration of nitrogen of $40 \%$ while the lowest value was presented by sample \#6, Figure 3d, with $15 \mathrm{~nm}$ of depth, with maximum atomic concentration of nitrogen of only $\sim 7 \%$. All the analyzed samples presented thin layer of oxygen as expected for this material, concerning to the passive layer that protects the material bulk of corrosion.

Through AFM technique, it was obtained the surface topography of samples \#4 and \#5, treated according to PIII (150 minutes) and PIII (75 minutes) + PN (240 minutes), respectively, which are presented in Figures $3 \mathrm{a}$ and $3 \mathrm{~b}$. The AFM results confirm the AES data in the sense that the sample \#4 (which is the counterpart of sample \#2) presented larger RMS rugosity of $6.9 \mathrm{~nm}$ compared to $1.8 \mathrm{~nm}$ of sample \#5 (counterpart of sample \#6). Also the values of the maximum depth of the rugosity, $\mathrm{R}_{\mathrm{y}}$, were 53.4 and $18.0 \mathrm{~nm}$ respectively for the same samples. These results can also be seeing in the Figures $4 \mathrm{a}$ and $4 \mathrm{~b}$.

The above results evidenced the surface hardness increase of all the samples compared to reference sample as expected that could improve the wear resistance of Ti-6Al-4V titanium alloy.

\section{Conclusions}

The nanoindentation results confirm the increase in surface hardness for both, single (PIII) and two steps (PIII $+\mathrm{PN})$ processes being about $29.8 \%$ for the first and $59.6 \%$, for the last compared to untreated sample.

The increase in surface hardness is due to nitrogen implanted layer confirmed by the nitrogen profile measurente by AES technique.

The thickest layer of $65 \mathrm{~nm}$ was presented by single step processed sample, PIII ion implanted during 150 minutes.

The thinnest layer of $15 \mathrm{~nm}$ was presented by two step processed sample (PIII during 75 minutes + PN during 240 minutes). This result

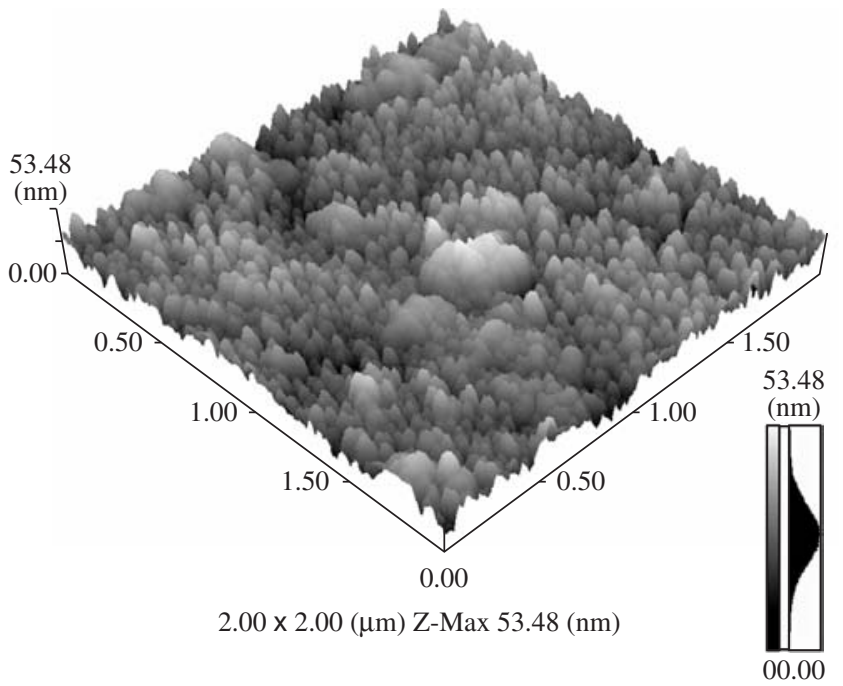

(a)

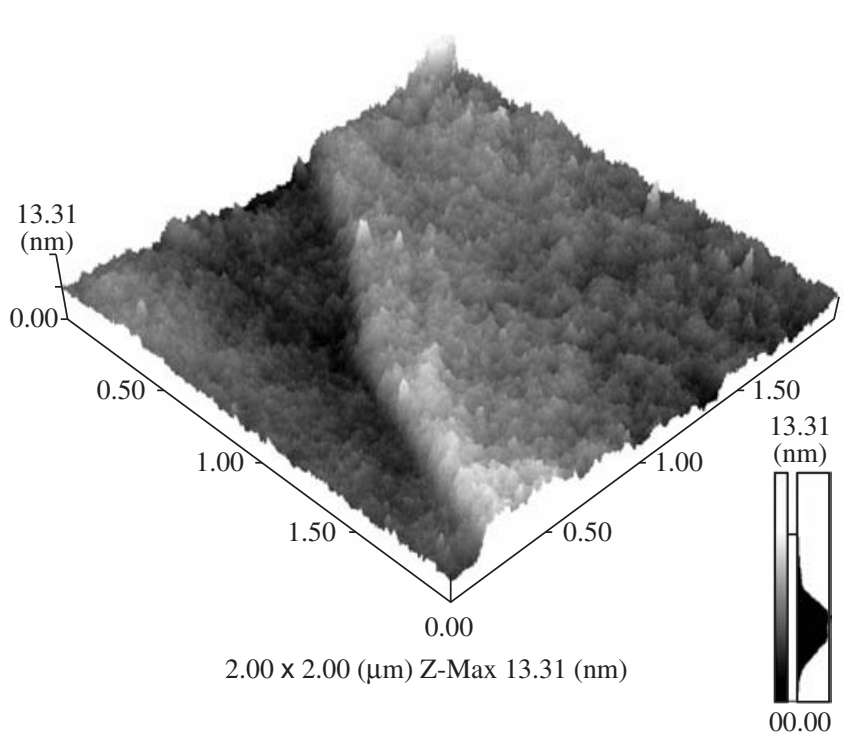

(b)

Figure 4. a) AFM - sample \#4 - PIII (150 minutes); and b) AFM - sample \#5 - PIIIP (75 minutes) + NP (240 minutes).

could be attributed to the nitrogen sputtering during the second step PN processing.

It was also evidenced that among the several procedures, the best result was obtained for the material processed according to PIII during 150 minutes.

New combinations of processing parameters are being carried out aiming thicker layer of implanted nitrogen.

\section{Acknowledgments}

This project partially is supported by the FAPESP.

\section{References}

1. Khan MA, Williams RL, Williams DF. The corrosion behavior of Ti6Al-7Nb and Ti-13Nb-13Zr in protein solutions. Biomaterials. 1999; 20(7):631-637. 
2. Cai Z, Nakajima H, Woldu M, Berglund A, Bergman M, Okabe T. In vitro corrosion resistance of titanium made using different fabrication methods. Biomaterials. 1999; 20(2):183-190.

3. Uo M, Watari F, Yokoyama A, Matsuno H, Kawasaki T. Tissue reaction around metal implants observed by X-ray scanning analytical microscopy. Biomaterials. 2001; 22(7):677-685.

4. Mante FK, Baran GR, Lucas B. Nanoindentation studies of titanium single crystals. Biomaterials. 1999; 20(11):1051-1055.

5. Baur K, Hornes J. The formation of intermetallic compounds in ion implanted aluminum and Ti-6Al-4V observed by X-ray absorption spectroscopy. Surface Science. 1999; 436(1-3):141-148.

6. Apert Ch. Metaux-Complements sur les metaux et alliages. Class notes: École Nationale D’ingénieurs de Constructions Aeronautiques, Toulouse; 1976.

7. Raikar GN, Gregory JC, Ong JL, Lucas LC, Lemons JE, Kawahara D, Nakamura M. Surface characterization of titamium implants. J. Vac. Sci. Technology. 1995; A13(5):2633-2637.

8. Alonso F, Rinner M, Loinaz A, Oñate JI, Ensinger W, Rauschenbach B. Characterization of Ti-6Al-4V modified by nitrogen plasma immersion ion implantation. Surface and Coatings Technology. 1997; 93(2-3):305-308.
9. Brooks R C. Heat Treatment, Structure ans Properties of Nonferrous Alloys American Society for Metals. Book-American Society for Metals: University of Tennessee; 1982.

10. Nishiguchi S, Nakamura T, Kobayashi M, Kim HM, Miyaji F, Kokubo $\mathrm{T}$. The effect of heat treatment on bone-bonding ability of alkali-treated titanium. Biomaterials. 1999; 20(5):491-500.

11. Rinner M, Gerlach J, Ensinger W. Formation of titanium oxide films on titanium and Ti-6Al-4V by $\mathrm{O}_{2}$ - plasma immersion ion implantation. Surface Coatings Technology. 2000; 132(2-3):111-116.

12. Bulletin Timet. Properties and Processing Ti-6Al-4V. General Office, 1979.

13. Silva MM. Modificação de Propriedades Superficiais da Liga Ti-6Al-4V pelo Processo Implantação Iônica por Imersão em Plasma. [Unpublished thesis]. São José dos Campos - SP: Instituto Tecnológico de Aeronáutica; 2001.

14. Dong H, Bloyce A, Morton PH, Bell T. Surface engineering to improve tribological performance of Ti-6Al-4V. Surface Engineering. 1997; 13(5):402-406.

15. Qiu X, Dodd RA, Conrad JR, Chen A, Worzala FJ. Microestructural Study of Nitrogen-Implanted Ti-6Al-4V Alloy. Nuclear Instrument and Methods in Physics Research. 1991; B59/60:951-956.

16. Muster D, Hage MA, Rye KT, Stucky T, Cornet A, Mainard D. Plasma deposition. Plasma coating and ion implantation to improve metallic implants and prostheses. Mrs Bulletin. 2000; 25(1):25-32. 